\title{
La hermosa locura y el vértigo de los puentes de Königsberg Friedrich Hölderlin
}

\author{
Luis Alfonso Gómez Arciniega \\ Ruprecht-Karls-Universität Heidelberg \\ alfonsofae@gmail.com
}

In memoriam José Emilio Pacheco y a Octavio Paz en el centenario de su nacimiento.

En «El fin de los perseguidores», Giovanni Papini relataba los desenlaces desdichados de todos los enemigos del cristianismo: el marqués de Sade derritiéndose en la hoguera de la sinrazón en Charenton en 1814; Shelley, que escribió un provocador libro denominado Necesidad del ateísmo, devorado por Neptuno en el Golfo de los poetas; Hegel, que justificó la corona prusiana y que se jactaba de haber superado la religión con su edificio idealista, abatido por la cólera en 1831; Émile Zola que denigró al catolicismo, asfixiado mientras dormía en 1902; Friedrich Nietzsche, autor del $A n$ ticristo, loco en 1888 (Papini, 1984: 243). Stefan Zweig dedicó uno de sus ensayos más hermosos a explorar la vida de Friedrich Hölderlin, Heinrich von Kleist y Friedrich Nietzsche, quienes «terminan prematuramente su vida, con el espíritu destrozado y un mortal envenenamiento de los sentidos» (Zweig, 1981: 10). Mientras Goethe, dice Zweig, se juega la perfección, éstos luchaban afanosamente por la inmensidad. Se trata de seres posesos por el demonio, «esa inquietud in- 
nata y esencial a todo hombre que lo separa de sí mismo y lo arrastra hacia lo elemental» (Zweig, 1981: 11). En el ocaso de su vida, el autor de Werther se vuelve amo del demonio, mientras aquéllos terminan sus días «despedazados por su propia jauría como Dionisos» ${ }^{1}$. Tanto la vida de Goethe, como la de Hölderlin, Kleist y Nietzsche podrían resumirse en aquel apotegma que Lars von Trier pone en boca de la protagonista de Nymphomaniac: "Quizás la única diferencia entre yo y otras personas sea que yo siempre le he pedido más a la puesta del sol. Colores más espectaculares cuando el sol toca el horizonte. Puede que éste sea mi único pecado» ${ }^{2}$. Zweig sostiene que la naturaleza demoníaca que desprecia la realidad los vuelve eternos rebeldes, verdaderos tránsfugas del orden de las cosas que prefieren quebrarse y despeñarse en el magma de lo absurdo antes que ceder al orden establecido. Goethe se subordina a una naturaleza conciliadora porque la concibe como la fuerza más alta, algo que adora en todas sus formas y aspectos (Zweig, 1981: 19). Papini, Zweig y Von Trier son heraldos de una verdad milenaria: raras veces conceden los dioses perdón a quienes osan abrir los sarcófagos de las entrañas divinas.

Conviene una digresión para mostrar por qué el análisis de la visión del mundo en Friedrich Hölderlin es determinante allende las fronteras de la literatura, filosofía o filología. Copan los diarios las noticias sobre Ucrania. En el frío lenguaje de la geopolítica, aquel territorio se debate entre el acercamiento al experimento de integración en Europa occidental y la permanencia en la esfera de influencia rusa. De

Loc. cit.

2 Nymphomaniac, Dinamarca-Alemania-Francia-Bélgica-Reino Unido, Lars von Trier, Zentropa Heimatfilm, 2014 (película). 
un lado, se preguntan qué tan lejos llegará Rusia para defender sus intereses; de otro, el mundo espera una reacción proveniente de Berlín, pues parece como si Alemania se hubiera convertido de facto en la fuerza motriz de la Unión Europea (Cohen y Krauel). Oscila entre esos extremos el péndulo ucraniano: los que se aferran a Europa como salvavidas de la corrupción y anhelan el bienestar de sus contrapartes daneses y los que privilegian la pertenencia a una comunidad eslava oriental; los jóvenes que simpatizan con los valores e ideales europeos y la generación más vieja que prefiere retener los contactos con Rusia; $64 \%$ del Este del país que apoyaría una unión aduanera y $66 \%$ del Occidente que secundarían la adhesión a la Unión Europea, según una encuesta del Instituto Internacional de Sociología de Kiev; las firmes intenciones de modernización económica y la nostalgia por el comunismo (Figes). Entre esos dos polos se dirime el futuro de Ucrania. Lo que invita a pensar, primero, en la <realidad global> europea y, segundo, en el liderazgo de Alemania.

El texto no abundará en cuestiones políticas, pero es primordial esbozar algunas preguntas que sitúan el análisis de la concepción de lo real en Friedrich Hölderlin a la luz de los acontecimientos actuales. ¿Qué tipo de decisión ontológica se realiza al intentar pertenecer a la UE? ¿Se abandonan coordenadas burocrático-autoritarias para abrazar una tiranía peor conformada por la supremacía de la producción económica y la completa supeditación de todas las demás formas de vida? La decisión y el destino de Ucrania invitan a pensar la realidad europea. Si las políticas económicas, el concepto de productividad y hasta las medidas de austeridad se dictan en Berlín, ¿qué responsabilidad tiene Alemania como actor global? ¿Será capaz de tomar un liderazgo espiritual? ¿A qué Alemania da la bienvenida Europa? 


\title{
¿Para qué poetas en tiempos aciagos?
}

\begin{abstract}
¿Cómo tender el puente, y en qué medida va a servir de algo tenderlo? La praxis intelectual [sic] de los socialismos estancados exige puente total; yo escribo y el lector lee, es decir que se da por supuesto que yo escribo y tiendo el puente a un nivel legible. ${ }^{Y}$ si no soy legible, viejo, si no hay lector y ergo no hay puente? Porque un puente, aunque se tenga el deseo de tenderlo y toda obra sea un puente hacia y desde algo, no es verdaderamente puente mientras los hombres no lo crucen. Un puente es un hombre cruzando un puente, che. Una de las soluciones: poner un piano en ese puente, y entonces habrá cruce. La otra: tender de todas maneras el puente y dejarlo ahí; de esa niña que mama en brazos de su madre echará a andar algún día una mujer que cruzará sola el puente, llevando a lo mejor en brazos a una niña que mama de su pecho. Y ya no hará falta un piano, lo mismo habrá puente, habrá gente cruzándolo. Pero andá a decirle eso a tanto satisfecho ingeniero de puentes y caminos y planes quinquenales.
\end{abstract}

-Julio Cortázar, Libro de Manuel

Si el continente, en su atroz ceguera, estuvo a punto de fenecer por guerras fratricidas, ahora lo está por la subordinación total de las ramas humanas del conocimiento a criterios económicos. Mientras el péndulo ucraniano se mueve a toda velocidad, las elites rematan un tratado de libre comercio con Estados Unidos. Las negociaciones ocurren mientras el presidente Obama afirma que «se puede hacer mucho más, potencialmente, con habilidades industriales o con un oficio que con una licenciatura en historia del arte» (Elperin). Valoraciones de eficiencia se imponen sobre significaciones culturales. Fernando Escalante decía: «Los programas, leyes, reglamentos repletos de productividad, eficiencia, rendi- 
miento, vínculos con el sector productivo [...] al final, con todo su ostentoso pragmatismo, [son algo] inevitablemente estéril» (Escalante). Ha llovido mucho desde que la filosofía, la literatura y el arte han sido declaradas obsoletas y disciplinas como la sociología, ciencia política o antropología fueron colonizadas por una matematización que aspira hacer de ellas ciencias funcionales (ordenadas bajo cierto sistema económico). Bolonia fue por muchos siglos sinónimo de pensamiento crítico. Salamanca, París, Oxford o Heidelberg se erigieron bajo sus premisas. Ahora evoca reformas educativas que tienen por objeto hacer de los estudiantes perfectos trabajadores de empresas, sepultando así el pensamiento crítico bajo los imperativos de los rankings y las necesidades del mercado global ${ }^{3}$. Contra todo lo que pudiera parecer, el fenómeno no es exclusivo de Europa, pues Felipe Curcó ya ha advertido de la tendencia de las universidades latinoamericanas a distanciarse de los problemas nacionales para enfocarse en las «corrientes principales〉 del pensamiento global, predominantemente anglosajonas (Curcó, 2013: 31).

¿A qué puerto se busca arribar con este preámbulo sui generis? Es la cartografía de una realidad global en la que Europa se encuentra inserta y que alienta la formulación de

3 La Declaración de Bolonia lo expresa en los siguientes términos: «La adopción de un sistema de títulos de sencilla legibilidad y comparabilidad, a través de la introducción del Diploma Supplement, con tal de favorecer la employability (ocupabilidad) de los ciudadanos europeos y la competitividad internacional del sistema europeo de enseñanza superior» (Joint Declaration of the European Ministers of Education). A partir de ahí, los comunicados han hecho menciones sucesivas al propósito firme de orientar la universidad a criterios económicos. Véase, por ejemplo, Ministros responsables de la Educación Superior de los países que participan en el Proceso de Bolonia, Comunicado de Londres de 18 de mayo de 2007. Hacia el Espacio Europeo de Educación Superior: respondiendo a los retos de un mundo globalizado. http: / / europa.eu/legislation_ summaries/education_training_youth/lifelong_learning/c11088_es.htm. 
nuevas disquisiciones. ¿Se requiere un poeta para señalar los problemas de un escenario sociopolítico sin cabida para manifestaciones culturales, improductivas desde un punto de vista económico? ¿Qué poeta? ¿Homero, Lucrecio, Quevedo, Bocaccio o Petrarca? El destierro que experimenta el ser humano hace pensar que se precisa alguien como Friedrich Hölderlin, <el poeta de los poetas〉 que proclama la esencia lírica, es decir, la parousia, la realidad absoluta del ser (Heidegger, 2012a: 34). Mientras otros filósofos sólo desean su presencia sin poder nombrarlo, Hölderlin, accede mediante la palabra.

Esta decisión adquiere gradaciones. Primero, si el liderazgo político de Europa está en Berlín, ¿por qué no convocar a un poeta alemán que señale aquello que se ha desvanecido en aras del éxito económico? Segundo, se trata de un pensador que resurge cuando las Parcas afilan las tijeras: nacido bajo el sino de las guerras napoleónicas y la Revolución francesa; rescatado antes de la Primera Guerra Mundial por el último aliento de Norbert von Hellingrath, antes de que éste regara con su sangre las trincheras de Verdún o evocado por Martin Heidegger en vísperas de la Segunda Guerra Mundial. Ahora, después de otra buena dosis de tragedias, vuelve a hacerse presente en horas infaustas.

El texto aspira, al menos, a poder trazar una cartografía $y$, en esta empresa, lo primero que deslumbra es la vocación de arquitecto del poeta: sus puentes unen archipiélagos prima facie irreconciliables. ¿Acaso no lo son todos los poetas de cierta forma? ¿No fue Rubén Darío gozne entre la vanguardia francesa y la vitalidad latinoamericana? ¿No le tiende Guillaume Apollinaire una soga al surrealismo desde la costa segura del simbolismo? Cierto. Sin embargo, en Hölderlin, el puente encarna tonalidades ontológicas porque el escritor 
concibe la historia armónicamente contrapuesta (Mas, 1999: 73). Ser puente es su raison d'être, porque sólo con esta característica inherente al ser se pueden vislumbrar las cúpulas de las grandes ciudades que edificó con el lenguaje. A sugerencia del germanista Vietor tomo, por ejemplo, una de sus primeras composiciones poéticas de 1797 titulada «Dios del sol». Tres estrofas anudan pasado, presente y futuro: en la primera, se poetiza de forma retrospectiva -utilizando con autoridad el pretérito perfecto compuesto- la puesta del sol; en la segunda, la tierra se hace presente desde el sentimiento de pertenencia (Zugehörigkeitsgefühl) que la vincula con el poeta; $y$, finalmente, en la tercera se yuxtapone un futuro de alborada donde el astro con luz propia volverá a estar junto con la tierra, anhelo perenne de los amantes (Viëtor, 1920: 341). No se pretende restringir el estilo personal de poetizar a una deslavada lucha hegeliana de tesis y antítesis porque en Hölderlin hay una aspiración muy distante a esos compartimientos estancos que cercenan la palabra. Noblesse oblige: se reconoce la inspiración, pero, en el mundo hölderliniano, los contrarios semejan esa mítica serpiente, uróboros, que se muerde la cola llevando en sus escamas el camino de sangre de la historia; Caín y Abel; Salomé con la cabeza de Juan Bautista; las puñaladas a Julio César; Abelardo y Eloísa; Marat y Séneca desangrándose en la bañera... el mundo in toto: rojo y negro; guerra y paz; noches blancas y días de guardar; la comedia humana y el tiempo perdido. Diseña puentes consciente de que «lo que permanece, lo fundan los poetas»:

Los poetas son ánforas sagradas donde se guarda el vino de la vida, el alma de los héroes (Hölderlin, 1909:356). 
Reparaba Gottfried Benn: «las obras de arte son fantásticas, pero históricamente inoperantes, carentes de cualquier efecto práctico. Ahí reside su grandeza»(Benn, 2006: 147). Hölderlin erige su «visión del mundo» como vasos comunicantes que resarcen la grandeza imperial de Königsberg, perdida entre las sombras de un palimpsesto, arrasada en la Segunda Guerra Mundial, pero entrelazada, originalmente, por siete puentes. El texto obedece a esta estructura y rinde homenaje a un asentamiento humano pretérito con la convicción de que, después de las atrocidades, sólo quedarían la poesía y el lenguaje. No es azarosa la elección. La ciudad donde Kant presentó en 1770 su disertación inaugural De mundi sensibilis atque intelligibilis forma et principiis fue pulverizada en tres etapas: por los aviones británicos, por la artillería aliada en 1945, y por la sistemática desgermanización planeada por la Unión Soviética -entre 1960 y 1985 desaparecieron las ruinas de 18 iglesias- (Köster, 2000: 10; Heidegger, 1984: 27). Se trató del holocausto de una urbe cuyos puentes originales, fácilmente identificables en un plano de Joachim Bering de 1613, fueron parte de un problema matemático que devanó los sesos a Euler ${ }^{4}$. Un lugar al que sólo puede accederse mediante la palabra. El poeta, orfebre del verbo, resguarda la memoria. Que las ciudades se hayan disuelto en torbellinos de polvo no es óbice para que el lenguaje actualice espacios pretéritos. En 〈Piedra de sol〉, Octavio Paz (1983: 238) erige, por ejemplo, una villa mexicana en el cuerpo de la mujer amada:

4 Krämerbrücke, Schmiedebrücke, Alte Dombrücke, Honigbrücke, Holzbrücke, Köttelbrücke, Grüne Brücke. Actualmente, sólo existen el Honigbrücke y el Holzbrücke. 
Voy por tu cuerpo como por el mundo,

tu vientre es una plaza soleada,

tus pechos dos iglesias donde oficia

la sangre sus misterios paralelos,

mis miradas te cubren como yedra,

eres una ciudad que el mar asedia,

una muralla que la luz divide

en dos mitades de color durazno,

un paraje de sal, rocas y pájaros

bajo la ley del mediodía absorto.

José Emilio Pacheco (1984: 27-28) en <Alta traición〉 llora una metrópoli perdida y alude el viejo axioma de Heráclito «Ningún hombre puede cruzar el mismo río dos veces, porque ni el hombre ni el agua serán los mismos»:

No amo mi patria.

$\mathrm{Su}$ fulgor abstracto

es inasible.

Pero (aunque suene mal)

daría la vida

por diez lugares suyos,

cierta gente,

puertos, bosques de pinos,

fortalezas,

una ciudad deshecha,

gris, monstruosa,

varias figuras de su historia,

montañas

-y tres o cuatro ríos. 
Siete puentes edifica Hölderlin para aspirar a la totalidad: un propósito que rebasa la condición humana y se disuelve irremediablemente en una hermosa locura.

Clasicismo y Romanticismo en comunión con el Ser

Le romantisme est une grâce, céleste ou infernale, à qui nous devons des stigmates éternels. -Charles Baudelaire, Salón de 1859.

Para los ilustrados del xVIII, en sólo cuestión de tiempo, la razón triunfaría. Cambió de guardia con el siglo. La Europa del XIX morirá eternamente agradecida. Gigantomaquia: Goethe y Schiller sostienen el Parnaso espiritual. Geranios de primavera: Heinrich von Kleist imagina el cálido vértice del amor diluyéndose en el suicidio con el combate amoroso de Aquiles y Pentesilea inmersos en un torbellino de amazonas guerreras; Jean Paul erotiza sin palpar, extraña sin abrazar, crepúsculo sin orgasmo, fuego sin ignición, lluvia sin torrente... Weltschmerz. Arquitectura filosófica de la mejor ley: Fichte se regodea con el Yo; Herder explora culturas en los confines de la tierra, dibuja genealogías, concibe árboles de heráldicas, traza pinceladas de etnografía.

Con la misma decisión con la que los franceses toman las armas y se sienten dueños del espíritu universal al que cargan en barricadas en ese ‘torbellino de los siglos> que es París -Victor Hugo dixit-, se gesta una revuelta del espíritu en Alemania. Allende del Rin todo es acción. Los alemanes urden las redes del destino, pero lo hacen desde escritorios de roble, buhardillas luminiscentes en casas de entramado, fachadas majestuosas, desde la universidad. En 1781, Kant 
publicó la Crítica de la razón pura y, en 1806, Hegel escribió la Fenomenología del espiritu. Obras cumbre del pensamiento occidental, darán al mundo algo para entretenerse durante buena parte del siglo entrante. Acuden a la cita con la historia Herder, Fichte, Goethe, Schiller, Schelling, Schleiermacher, Hölderlin; Pierre Bertaux interpretó la obra del último como una «sostenida metáfora de la Revolución`(Barrios, 2001: 18). La francesa fracasa en el plano de las instituciones políticas, pero los alemanes triunfan en el combate de las ideas.

Todos los estudiosos de Hölderlin concuerdan en que, aunque comparta temas y puntos de vista de unos y otros, no cabe situarlo ni entre los representantes del Clasicismo ni entre los románticos (Mas, 1999: 23). Proyectó un puente entre escuelas y siglos. Los une en la aspiración del Seyn a reunirse con la totalidad de la naturaleza. Así se distancia del idealismo trascendental (Voßkühler, 2004: 53). Lo realmente decisivo sólo puede pronunciarse por los poetas (Mas, 1999: 55). En su fulminante texto filosófico Juicio y ser propone el 〈Ser absoluto〉 frente al 〈Yo absoluto〉 de Fichte (Voßkühler, 2004: 53). Inmaculada unión de sujeto y objeto, el 〈Ser〉 sólo puede aprehenderse en una «intuición intelectual〉 (Mas, 1999: 56). Gottfried Benn, citado supra, dedica unas líneas a estos afanes:

El poeta, nacido azarosamente en la ambigüedad del ser, hundido por la lluvia del Aqueronte en una individualidad impenetrable, moldea y estructura conceptos y así se yergue por encima del realismo brutal de la naturaleza, del ciego e indomable principio de causalidad, de la infame timidez del conocimiento escaso y sólo así logra una estructura legitimadora (Benn, 2006: 152). 
Reflexiones que rebasan lo kantiano y respuestas que trascienden lo romántico, inicia así la arquitectura de su particular concepción de lo real.

La escalera al cielo bien fincada al suelo: el arpa de Alemania

Wenn Novalis davon spricht, dass er an die Gestalten von Brot und Wein glaube, so sollte man ihm keinen anderen Glauben entgegenbringen, als den, den er selbst hat: er meint nämlich, dass Alles Brot und Wein sein kann.Er glaubt an die Bibel, aber jedes echte Buch ist eine Bibel; an das Geniem aber jeder Mensch ist ein Genie; an den Deutschen, aber

Deutsche gibt es überall, die Deutschheit ist für ihn, trotz des angeblichen historischen Empfindens der Romantik, nicht auf Staat und Rasse und nicht einmal aus Deutschland beschränkt [...]. Er rühmt die Antike, aber Antike ist überall, wo echter Geist ist; er bekennt sichals Royalisten und Monarchisten, aber alle Menschen sollen trohnfähig werden"; er liebt nur seine Frau, aber er kann sie mit Hilfe seiner

Phantasie in tausend andere Frauen verwandeln. -CARl SchmitT, Politische Romantik

Si sólo se puede acceder al ser mediante la poesía, Hölderlin aventura una caracterización más: el poeta se ocupa de las cosas trascendentales, pero tiene los pies hundidos en el suelo natal, es decir, en lo nacional. Del ser se puede decir poco, pero si sólo es intuido por el lenguaje, entonces, se deduce que es histórico, en tanto vinculado con una determinada genealogía lingüística. Por esta razón, los poetas son caracterizados como <escaleras al cielo〉. Ciertamente, como escribe el filósofo 
Dilthey, las impresiones del paisaje moldearon el sentimiento de la naturaleza en Hölderlin: lagos inabarcables con horizontes malvas y ocres crepusculares liberaban el alma (Dilthey, 2005: 226). Como pocos, el poeta dibuja la belleza de su patria con el pincel del verbo: dedica himnos a sus ríos -el Meno, el Neckar, el Rin, las fuentes del Danubio-, alaba sus ciudades -Heidelberg, Stuttgart o su Heimat-, canta sus paisajes, celebra a sus mujeres y arenga a defender la patria: «iVive, allí arriba, patria, y no cuentes los muertos! Que para ti, no cayó de más uno, ipatria amada!» (Hölderlin, 1909: 194).

Heidegger es tajante: «Si se abandonan las leyes históricas, la humanidad cae en lo anti histórico» (Heidegger, 1984: 179). Para que esto no suceda, se ha dado al ser humano el lenguaje que no se agota en su función heurística: ofrece la posibilidad de ser en medio del campo abierto de lo cósico; sólo donde hay lenguaje hay mundo. Sólo donde hay mundo hay historia (Heidegger, 2012a: 36). En clave heideggeriana, el idioma poético era una llave que no sólo abría la posibilidad misma de la comunicación cotidiana, sino el reconocimiento del destino histórico del pueblo alemán. Hellingrath coincidía: «Lo nacional no es la procedencia o el aparato estatal. Todos los caminos nos llevan al lenguaje, el alma del Volk; fuera de éste se agota lo nacional, corazón de la nación» (Von Hellingrath, 1921: 21). Carl Schmitt aducía «que sólo en el tiempo histórico crecía la humanidad» (Schmitt, 1925: 93). La poesía no es un adorno del Dasein, prosigue Heidegger (2012: 42). La poesía es el protolenguaje de un pueblo histórico porque nombra el ser y la esencia de todas las cosas (Heidegger, 2012: 47). En su análisis del 〈Himno del Ister〉, el anacoreta de Messkirch se percata del delicado ligamen a lo nacional que esboza Hölderlin: «Cuando Hölderlin dice «tierra», se refiere a lo Heimische. «Hertha〉 proviene de Nerthus, 
el concepto germano para terra mater» (Heidegger, 1984: 23, 35 y 36$)$.

La roca es buena para la pradera,

lo seco, para el abrevadero.

Lo húmedo, en cambio, para la comida.

Si uno quiere vivir

aunque sea en escaleras,

y donde se recuesta una casita,

detente junto al agua (Hölderlin).

La palabra poética construye escaleras para que lo celestial descienda y por esta razón deben tener los poetas los pies bien anclados al suelo (Heidegger, 1984:195). Hellingrath, desafiando la corriente popular que describía Alemania como la tierra de Goethe, contraponía: «Nos denominó el <pueblo de Hölderlin` porque en su producción lírica se encuentran secretos vedados para aquellos que no son alemanes» (Von Hellingrath, 1921a: 17).

La Acrópolis y el Valhalla

Das griechische Ideal der Menschheit war vollkommene Eintracht und Ebenmass aller Kräfte, natürliche Harmonie. Die Neueren hingegensind zum Bewußtsein der inneren Entzweiung gekommen, welche ein solches Ideal unmöglich macht; daher ist das Streben ihrer Poesie, diese beiden Welten, zwischen denen wir uns geteilt fühlen, die geistige und sinnliche, miteinander auszusöhnen und unauflöslich zu verschmelzen. Die sinnlichen Eindrücke sollen durch ihr geheimnisvolles Bündnis mit höhe- 
ren Gefühlen gleichsam geheiligt werden, der Geist

hingegen will seine Ahnungen oder unnennbaren Anschauungen vom Unendlichen in der sinnlichen

Erscheinung sinnbildlich niederegen.

-August Wilhelm SCHLEgel,

Vorlesungen über dramatische Kunst und Literatur

Hölderlin suponía que la mejor manera de exaltar la historia y cultura propias era exponiéndolas a la prueba del mundo. Alemania tenía, entonces, que buscar un 〈otro〉. ¿Quién mejor que Grecia? Para volverse alemanes presentes había que viajar al pasado. Entonces, el caminante alcanza el tercer puente de esta ciudad que el poeta suabo empieza a construir. Hölderlin experimenta con los tiempos. Pasado, grieguidad (Griechentum); futuro, germanidad (Deutschtum). El alemán y el griego antiguos eran, desde su perspectiva, las únicas lenguas capaces de transmitir pensamiento filosófico de primer orden.

Grecia no revivirá en una suerte de palingenesia en Alemania. Grecia es sólo Grecia, y está muerta. La recuperación de lo griego tiene detalles técnicos: los poemas son bautizados como cánticos; son sonoros imitando las sílabas largas y breves de los pies de la métrica grecolatina; en «Archipiélago»y «Patmos», verdaderas épicas, se dan cita momentos estelares de Grecia: su bella geografía; sus templos con sus pórticos, columnas dóricas, las estatuas; Filipo a Alejandro Magno, «ya no cabes en Macedonia. Busca un reino a la medida de tu grandeza»; Heráclito, «el camino que sube y el camino que baja son uno y el mismo»; el templo de Artemisa; la lucha de los persas contra los griegos; la grandiosa batalla naval de Salamina; los barcos desplegados con sus banderas en los sinuosos rescoldos del mar Egeo... todo se decanta con 
nitidez desde los hexámetros (Pau, 2008: 265). En las antípodas de aquella versión renacentista de escenográfico acartonamiento, se distancia del fetichismo de objetos culturales presente en Winckelman (Ferris, 2000: 159). Hölderlin evoca la conciencia griega de la afinidad entre naturaleza, hombres, héroes y dioses (Dilthey, 2005: 231). Como dice Modern (1986: 172), «vive en carne propia el ideal de la unión entre naturaleza y espíritu, entre lo humano y lo divino que los mitos griegos enuncian y su poesía prueba cabalmente».

Grecia, como cultura, es la síntesis lograda de naturaleza y espíritu. Después de las Cariátides de Atenas, del Doríforo de Policleto y las tragedias de Sófocles, ya nada más quedase por decir de una naturaleza humana, cuya esencia, Javier Hernández-Pacheco dixit, «se ha hecho en el arte transparente para el espíritu» (Hernández-Pacheco, 1995: 77). En la situación crítica de los territorios alemanes nunca lo abandonó el anhelo por una victoria como la de Salamina (Hernández-Pacheco, 1995: 232). Lo atlético, refiere Heidegger, es lo que devela a Hölder-

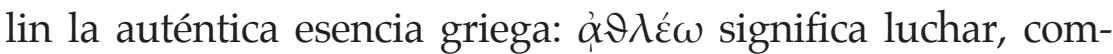
batir, coger y sostener (Heidegger, 2012: 160). Lo atlético es lo

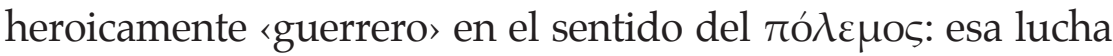
que Heráclito piensa como el movimiento en el cual y para el cual dioses y hombres salen afuera en la apariencia de su ser. ${ }^{5}$ Lo atlético del «cuerpo heroico〉 es el refulgir del espíritu que se abre paso luchando en su medida corporal y se capta en ello. 〈El más alto entendimiento en sentido griego〉 es 〈fuerza de reflexión`. Ambas cosas, prosigue Heidegger, lo atlético y la capacidad de reflexión, son las maneras, en sí mismas unidas, de llevar la belleza a refulgir. Lo atlético y la fuerza de reflexión

5 Loc. cit. 
hacen palpable la belleza, pertenecen a aquello que Hölderlin llama 〈ternura> (Zärtlichkeit), concepto que tuvo hasta el siglo XVII un sentido alto, relacionado con garbo y sensibilidad. ${ }^{6}$ En una versión crepuscular de 〈Patmos〉, Hölderlin llama a Grecia 〈la tierra juvenil de los ojos atléticos〉. Su mirada es, como toda auténtica mirada, espiritual, y brilla en lo corporal ${ }^{7}$.

Hölderlin también tomará la grandeza imperial romana para ornamentar su visión de Alemania. Empero, éste marca las fronteras entre un ente histórico y otro en «La muerte por la patria», donde canta la hazaña de las Arminio derrotando a Varano en Teutoburgo. Ahora, como antes, acaso pueda reformularse aquella frase que Friedrich Panzer pronunció el 13 de febrero de 1933 en un discurso en la Universidad de Heidelberg intitulado «Richard Wagner y la germanidad»: «Renovador del drama simple, descubridor del lugar de las artes en la sociedad humana, evocador poético de la reflexión vital del pasado, filósofo, historiador, esteta y crítico, maestro del lenguaje de la mitología y del poema mítico» (Panzer, 1953: 2).

El profeta y los dioses huidos

I went to the Garden of Love. And I saw what I never had seen: A Chapel was built in the midst, where I used to play on the green. And the gates of this Chapel were shut and Thou shalt not, writ over the door; so I turn'd to the Garden of Love,

6 Loc. cit.

7 Loc cit. 
that so many sweet flowers bore, and I saw it was filled with graves, and tomb-stones where flowers should be: and Priests in black gowns, were walking their rounds and binding with briars, my joys Edesires. -William Blake, The Garden of Love

Ciertamente, Hölderlin concibe a los alemanes como herederos de los griegos en el arte de filosofar, pero no se puede volver a la Antigüedad clásica porque los dioses se han ido. Entonces, el poeta diseña un cuarto puente para poner al ser humano en alcance con lo divino. La humanidad ha experimentado un proceso de Entgötterung (huida de los dioses). No sólo se trata de las deidades griegas, el poema 〈Patmos〉 hace una clara referencia al Apocalipsis de San Juan: «Cerca y difícil de coger está el dios. Pero donde está el peligro, crece también lo salvador» (Hölderlin, 1909: 347). Para Hölderlin, los dioses no son esos «hermosos espíritus de la tierra de fábulas», en palabras de Schiller, sino poderes decisivos en la vida, en el cosmos, naturaleza y hombres. La vida en el mundo -incluso en el sobrenatural- recupera su dignidad metafísica y santificación llegando a una superación religiosa del materialismo (Ibel, 1948: 19:20).

El poeta habla por el Dios oculto. Su tarea es profética: ser el heraldo del Dios ausente. En mitad de la noche e indefenso por la vida proclama a los hombres el retorno, pero éstos no sólo lo ignoran, sino lo persiguen (Pau, 2008: 261). Después de la partida del panteón grecolatino y del Dios cristiano, Heidegger diagnosticaba en una conferencia en la Universidad de Heidelberg la completa dominación de lo técnico-industrial sobre la tierra, inscrita ya para ese entonces en un espacio cósmico interestelar que ya se proyectaba 
como espacio de acción del ser humano (Heidegger, 2012b: 176). Así, pensaba Heidegger, «el vínculo inagotable entre tierra y cielo, hombre y dios aparecía destruido» ${ }^{8}$. Salvar el recuerdo de los tiempos en que el hombre vivía en la proximidad de los dioses, es la tarea escatológica del poeta.

Se ha dicho que 〈Pan y vino〉 es una síntesis de la obra entera de Hölderlin, y que se trata de una composición en la que el autor expone su visión del mundo (ein weltanschauliches Lehrgedicht) (Pau, 2008: 221). En la séptima estrofa contrapone al hombre como «vasija frágil» que apenas puede «contener la plenitud divina breves instantes» y el papel del poeta como peregrino de aquellos territorios extraterrenos:

¡Pero amigo! Llegamos demasiado tarde. En verdad viven los dioses, pero sobre la cabeza allá arriba en otro mundo.

Sin fin actúan allí y parecen no prestar atención si nosotros vivimos, con tanto cuidado nos tratan los celestes. Pues no siempre puede darles cabida una vasija débil, solamente en ciertos tiempos soporta el hombre la plenitud divina.

Un sueño de ellos es después la vida. Pero la sala de los desvariados

ayuda, como adormecimiento, y la necesidad fortalece y la noche, hasta que héroes suficientes hayan crecido en la cuna de hierro, los corazones son en su fortaleza, como antes, semejantes a los celestes.

Tronando vienen entonces ellos después. Mientras tanto pienso a menudo

8 Loc. cit. 
que mejor es dormir, que estar así sin compañeros, que aguantar así, y qué hacer entre tanto y qué decir, no lo sé, ¿y para qué poetas en tiempos de penuria? pero ellos son, dices tú, como los sacerdotes sagrados del dios del vino,

los que fueron de un país a otro en noche sagrada (Hölderlin, 1909:318-319).

El arco entre el día y la noche

Die Eule der Minerva beginnt erst mit der einbrechenden

Dämmerung ihren Flug

—Friedrich Hegel, Grundlinien der Philosophie des Rechts

Se podría decir que el Romanticismo celebraba misas dedicadas a la noche: era la hora de la revelación poética. Para Novalis, Tieck o Wackenroder, los sueños proveen acceso a una «edad mística primigenia», llenando de sabiduría indescifrable a las mentes en despertar (Morton, 2000: 15). El ser humano prefiere 〈el día soleado〉 (der besonnene Tag), pero la oscuridad de la noche es la que sugiere los pensamientos más hondos al filósofo. La noche es, en definitiva, el origen de la filosofía (Pau, 2008: 220). Piénsese en Novalis, esencia misma del Romanticismo y contemporáneo de Hölderlin, que perdió a su prometida Sophie, de tan sólo trece años, y después de aquellas visitas al hospital en Jena que se pierden en la memoria como los barcos en la neblina del amanecer del puerto, transforma la poesía en un absoluto, una religión mediante la cual intenta acompañar a la dama en la muerte por aquellos rescoldos por los que Dante transitó en pos de Beatriz (Dilthey, 2005: 173-223). Para estos menesteres, Novalis lleva sus célebres «Himnos a la noche» donde rememora la «sacra, 
indecible, misteriosa nochè. Nada de flechas y sólo versos llevan en el carcaj los poetas cuando se adentran en la noche. Caminarán como sombras en este ámbito predilecto Baudelaire o Poe, pues también encontrarán ahí la manifestación poética (Onetto, 1995).

Además de profeta, rapsoda de las glorias nacionales y sacerdote del Ser, el poeta es un semidiós que tiene contacto con el mundo visible del día y lo invisible de la noche. Pero éste prefiere deambular por las tinieblas donde los versos se vuelven místicos en la hora de la creación poética. Heidegger analiza un fragmento de Heráclito en relación con la poesía de Hölderlin: «Una vez, en los comienzos del pensar occidental, la esencia del lenguaje destelló a la luz del ser»9 . Heidegger pensaba que los filósofos presocráticos pensaron desde el Logos la palabra como directriz para reflexionar sobre el ser. Ese rayo de luz se apagó y los filósofos comenzaron a centrarse en el Dasein, olvidando el Ser. Los poetas son los únicos seres que en la lenta noche caminada siguen refiriéndose al Ser. En su análisis del poema del río Rin, Heidegger encuentra la descripción de esa naturaleza de los poetas como semidioses. Su esencia es resistir y sostener dentro de aquella mitad o medio que existe entre dioses y hombres en y para la que se abre el todo del ente (Heidegger, 1999: 225-228).

Razón y locura: el amor como salvación

Bella y más segura que el azul del cielo con dulces ojos lánguidos y hermosos,

9 Loc. cit. 
donde acaso el amor brilló entre el velo del pudor que los cubre candorosos; tímida estrella que refleja al suelo rayos de luz brillantes y dudosos, ángel puro de amor que amor inspira, fue la inocente y desdichada Elvira.

Como pocos, Hölderlin vivió la escisión entre locura y razón en su propia carne y en el fracaso de su vida. Mientras Schelling se devana los sesos en búsqueda del sistema perdido, afirma Hernández-Pacheco, «Hölderlin averiguó muy pronto que la filosofía es conciencia de una escisión insuperable: muy especialmente entre el sujeto y la naturaleza» (Hernández-Pacheco,1995: 65). El poeta quiso superar la contradicción entre razón y locura en el amor.

Amor, recuerda Hölderlin en Hiperión, por parte del padre es heredero de una tendencia a rebasar todos los límites humanos, y, por parte de la madre, es heredero de la tendencia a mantenerlos. Pero radica en su naturaleza poner de acuerdo el conflicto de estas dos tendencias (Gabás, 2001: 50). De forma paralela, el amor es esfuerzo orientado a recobrar la unidad pensada como paraíso perdido. En una de sus cartas, Hiperión confiesa a Belarmino: «No éramos [él y Diotima] sino una sola flor, y nuestras almas vivían una en otra como la flor cuando ama y oculta sus tiernas alegrías en su cerrado cáliz» (Mas, 1999: 64). Si la razón aspira a decretar la finitud para ordenar todo en marcos teóricos, la locura muestra la limitación del ser cuando las ideas se desbordan del recipiente que las contiene. Sólo el Amor une estos dos impulsos antagónicos, pues para Hölderlin, explica Dieter Heinrich, «es la fuerza sintética que puede producir el estado en el que 
coincide lo opuesto y configura un todo armónico» (Heinrich, 1992: 65). Se trata de una provocación al racionalismo cartesiano, pero buscando no despeñarse del todo en los abismos de la sinrazón. La certeza se funda en el amor, en lo que se siente con el otro en lugar de en lo pensado por el ego cogito, se repite e intensifica en la referencia algo irónica del sujeto a sí mismo como mecanismo: se exige perder el juicio (Barrios, 2001b: 83). De esta forma, según Barrios, se disuelve el dualismo entre alma y cuerpo, o razón y sentimiento, pero también entre lo finito e infinito, lo que vendría a proponer la 〈filosofía de la unificación〉 esbozada por Hegel y Hölderlin en Frankfurt en torno a 1797 (Barrios, 2001b: 83-84).

\section{Pigmalión y Galatea}

Al fin, cuando con los cuerpos unidos ellos disfrutan de la flor de la edad, cuando ya el cuerpo presagia sus goces y Venus está a punto de sembrar los campos femeninos, ávidamente estrechan sus cuerpos y unen la saliva de sus bocas y respiran profundamente apretando los labios con sus dientes; pero todo es inútil, ya que no pueden arrebatar nada de allí ni tampoco penetrar o fundirse en un cuerpo con todo su cuerpo; pues a veces parecen querer y luchar por hacer eso: con tanta pasión se adhieren en las junturas de Venus, hasta que los miembros se derriten abatidos por

la fuerza de su placer.

En sus Metamorfosis, Ovidio narra el mito de Pigmalión, escultor chipriota que desde la soledad moldea formas femeninas en níveo marfil. Llegado el día en el que su creación superó la belleza de cualquier mujer terrena, su corazón des- 
bocó por aquel fuego ficticio. En su desesperación, aproxima sus manos a la obra rehusándose a creerla fría como lápida de mármol, anhelando el calor de la carne humana. Como Pigmalión, Hölderlin es orfebre de versos y su Galatea, Diotima, encarna en una hermosísima mujer, esposa de un banquero de Fráncfort: Susette Gontard (Augst, 2004: 151).

Si amor es el puente entre locura y razón, la musa encarnada conjuga los tres tiempos de la historia en Hölderlin: el pretérito cuando trazaba sus contornos con sus versos; el presente del encuentro místico con ese dechado de belleza griega, cabello castaño, revelación metafísica de la vida misma, confirmación y realización de la nostalgia interna, salvadora de emergencia espiritual, a veces Afrodita; otras, Madonna; ojos de un cuadro de Tiziano; el futuro donde cantará en un nuevo ciclo de poemas su partida ${ }^{10}$.

El puente del amor entronca con el puente de la musa, palabra cuya etimología hay que rastrear hasta el poeta Píndaro que en sus Olímpicas menciona mousike, refiriéndose por el sufijo -ikē a la habilidad especial o technē en las actividades (canto, música y baile) de las Musas (Naddaf, 2009: 56). Acaso de este origen provenga la inspiración de Hölderlin para escribir sus himnos pindáricos. Otro poeta, Homero, les construye una casa: el Monte Olimpo y Hesíodo sostiene que se trata de las hijas de Zeus y Mnēmosynē o la Memoria (Naddaf, 2009: 65). Naddaf aventura una hipótesis: si las Musas antecedieron de hecho a Homero y Hesíodo en la tradición griega, esto indicaría que la noción de una musa como fuente de inspiración fue un fenómeno poético antes que un fenómeno literario (Naddaf, 2009: 66). Aunque la etimología

10 Las descripciones de Susette Gontard son vastas. Véase Ibel (1948: 10); Von Hellingrath (1921: 54) y Dilthey (2005: 245). 
todavía es poco clara, Naddaf sugiere que existe conexión con las raíces *men- y *mnē-, vinculadas con estados mentales, es decir, 〈tener la mente conectada ${ }^{11}$. Reiteración: Gontard conjuga tres tiempos, la idealización que la preexiste, el presente en las mejores horas de los amantes en el bosque de Teutoburgo y los lamentos de Menón ante su partida. Si el poeta había construido una ciudad, ahora Diotima habría de habitarla (Ibel, 1948: 31).

Pero Hölderlin encuentra en Diotima también a Alemania. En Bad Driburg -escribe Hölderlin a su hermano-: «Bebí del agua que había allí, un agua excelente, fortificadora y purificadora [...]. Te alegrará especialmente saber que vivíamos a sólo media hora del valle en que Arminio venció a las legiones de Varo» (Pau, 2008: 138-139). En su «Canto del alemán», Hölderlin (1909: 197) exalta a las mujeres alemanas pensando en Diotima:

Gracias a las mujeres alemanas sean dadas, que nos conservaron de las imágenes divinas el apacible espíritu; y a diario repara de nuevo la clara, propicia paz, la confusión maligna.

En Andenken, Hölderlin recurre a Eolos para susurrar mensajes de amor a su adorada Susette. Si se entiende el viento como medio de comunicación entre los amantes, s. G. schöne Garonne puede entenderse como una reminiscencia (Pahl, 2005: 195). En su análisis, Katrin Pahl plantea que palabras que acumulan el sonido de efe y ese como 〈liebste〉, 〈feurigen〉,

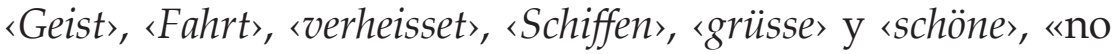

11 Loc. cit. 
sólo imitan el sonido del viento, sino que también transmiten las iniciales de los dos amantes: Friedrich y Susette ${ }^{12}$. Con el viento, piensa Pahl (2005: 196), «los amantes susurran el nombre del otro a través del tiempo y del espacio». En los cuatro años que van de 1799 a 1802 -muerte de Susette-, el poeta vuelve reiteradamente al dolor de la separación, a tal grado que su producción de este período puede organizarse en un ciclo de la despedida con composiciones como «Despedida», «Mi dominio» o «Los lamentos de Menón por Diotima». En la quincuagésima versión de Diotima, dice Hölderlin:

Podría decir el nombre de los héroes

y guardar silencio sobre la más bella de las heroínas ${ }^{13}$.

Sobrevivirá a Diotima más de treinta años. Solo y sin dioses.

\section{Consideraciones finales}

El lenguaje es potencia histórica para conmemorar y celebrar, para levantar las ciudades de su polvoroso exilio, para erigir de nuevo Königsberg y terminando, decir ufanamente que, después de las atrocidades de la guerra, tras la tecnificación del mundo, aún queda la poesía y el lenguaje. ¿Estarán ahora los tiempos maduros para el canto del poeta? Como las cosas pasan ahora tan rápido y ha corrido tanta agua bajo los puentes desde entonces, ya muchos han olvidado que los griegos estuvieron demasiado cerca de los dioses, quemándose con el resplandor del sol. ¿Habrá sucedido lo mismo

12 Loc. cit.

13 Friedrich Hölderlin, "Diotima", R. Ibel, op. cit., pp. 46-47. 
con los alemanes? Heidegger siempre pensó que Alemania debía orientar espiritualmente al mundo occidental. Hoy, el liderazgo ocurre en medio de un interesante experimento de integración que ha asegurado la paz al continente por muchos años. Es tiempo de pensar la concepción de lo real en Europa, para asegurar el futuro. Si los criterios de austeridad y eficiencia exterminan todo lo demás, el Quijote, Zaratustra y los dioses griegos partirán. Quizá no existan poetas para volver a señalar el camino.

Bibliografía

Augst, T. A. (2004). 〈A Nothing, If It Could Be Thought $>$ Shadows of Diotima in Susette Gontard's Letters to Friedrich Hölderlin. The German Quarterly, 77 (2), pp. 145-169.

Barrios, M. (2001a). Narrar el abismo, en su libro Narrar el abismo. Ensayos sobre Nietzsche, Hölderlin y la disolución del clasicismo. Valencia: Pre-Textos.

Barrios, M. (2001b). Hölderlin: la mirada del instante, en su libro Narrar el abismo. Ensayos sobre Nietzsche, Hölderlin y la disolución del clasicismo. Valencia: Pre-Textos.

Benn, G. (2006). Können Dichter die Welt ändern?, Bruno Hillebrand (ed.). Gottfried Benn. Essays und Reden in der Fassung der Erstdrucke. Fráncfort: Fischer.

Cohen, Josh. Will Putin Seize Crimea. The Moscow Times. Moscú, 23 de febrero de 2014, sec. Opinion, http: / / www. themoscowtimes.com/opinion/article/will-putin-seizecrimea / 495074.html, consultado el 25 de febrero de 2014. Curcó, F. (2013). Latin American Political Thought as a Response to Discourse Ethics (manuscrito). 
Dilthey, W. (2005). Friedrich Hölderlin. Das Erlebnis und die Dichtung (ed. Gabriele Malsch), Wilhelm Dilthey. Gesammelte Schriften tomo 26 (ed. K. Gründer y F. Rodi), Gotinga: Vandenhoeck \& Ruprecht, 3a ed.

Dilthey, W. (2005). Novalis. Das Erlebnis und die Dichtung (ed. Gabriele Malsch). Wilhelm Dilthey. Gesammelte Schriften tomo 26 (ed. K. Gründer y F. Rodi), Gotinga: Vandenhoeck \& Ruprecht, 3a ed.

Elperin, J. Obama takes a shot at a key part of his base - art history majors. The Washington Post, Washington, 30 de enero de 2014, sec. Post Politics, http:/ / www.washingtonpost.com/blogs / post-politics / wp / 2014/01/30 / obama-takes-a-shot-at-a-key-part-of-his-base-art-historymajors / , consultado el 27 de febrero de 2014.

Escalante, F. Zeitgeist. La Razón, México D.F., 25 de febrero de 2014, sec. Opinión, http: / / www.razon.com.mx/ spip. php? page $=$ columnista\&id_article $=206776$, consultado el 27 de febrero de 2014.

Ferris, D.S. (2000). The Recall of Thought: Hölderlin, en su libro Silent urns. Romanticismo, Hellenism, Modernity. Stanford: Stanford University Press.

Figes, O. Is There One Ukraine?. Foreign Affairs, 16 de diciembre de 2013, http: / / www.foreignaffairs.com/articles/140560 / orlando-figes / is-there-one-ukraine, consultado el 28 de febrero de 2014.

Gabás, R. (2001). El todo-uno del idealismo alemán en la poesía de Hölderlin. Enrahonar 32/33.

Heidegger, M. (2012a). Hölderlin und das Wesen der Dichtung (ed. Fiedrich-Wilhelm von Herrmann), Martin Heidegger, Gesamtausgabe, I. Abteilung: Veröffentliche Schriften 19101976, tomo IV: Erläuterungen zu Hölderlins Dichtung. Fráncfort: Vittorio Klostermann, $3^{\mathrm{a}}$ ed. 
Heidegger, M. (2012b). Hölderlins Erde und Himmel (ed. Fiedrich-Wilhelm von Herrmann), Martin Heidegger, Gesamtausgabe, I. Abteilung: Veröffentliche Schriften 1910-1976, tomo IV: Erläuterungen zu Hölderlins Dichtung, Fráncfort: Vittorio Klostermann, $3^{\mathrm{a}}$ ed.

Heidegger, M. (1999). Hölderlins Hymnen Germanien und Der Rhein (ed. S. Ziegler), Martin Heidegger, Gesamtausgabe II. Abteilung: Vorlesungen 1923-1944, vol. 39, Fráncfort, Vittorio Klostermann, 3a ed.

Heidegger, M. (1984). Hölderlins Hymne Der Ister (ed. W. Biemel), Martin Heidegger, Gesamtausgabe II. Abteilung: Vorlesungen 1923-1944, vol. 53, Fráncfort, Vittorio Klostermann.

Heinrich, D. (1992). Der Grund im Bewusstsein. Untersuchungen zu Hölderlins Denken (1794-1795), Stuttgart: Klett-Cotta.

Hölderlin, F. (1909). Gesammelte Werke, (ed. Wilhelm Böhm), tomo II: Friedrich Hölderlin. Gedichte, Jena, Eugen Diederichs.

Hölderlin, F. Der Adler, http: / / www.hoelderlin-gesellschaft. info / index.php?id=963, consultado el 25 de febrero de 2014 .

Hernández-Pacheco, J. (1995). La conciencia romántica con unas antologías de textos, Madrid: Tecnos.

Ibel, R. (1948). Hölderlin und Diotima. Dichtungen und Briefe der Liebe, Hamburgo: Christian Wegner.

Joint Declaration of the European Ministers of Education, The Bologna Declaration of 19 June 1999, http: / / www. ond.vlaanderen.be / hogeronderwijs / bologna / documents / MDC/BOLOGNA_DECLARATION1.pdf.

Köster, B. (2000). Königsberg. Architektur aus Deutscher Zeit. Husum, Husum Druck und Verlagsgesellschaft.

Krauel, T. Janukowitsch ist reif für den Strafgerichtshof. Die Welt, Berlín, 20 de febrero de 2014, sec. Opinion. http: / / www.welt.de / debatte/kommentare / article125052531 / 
Janukowitsch-ist-reif-fuer-den-Strafgerichtshof.html, consultado el 25 de febrero de 2014.

Mas, S. (1999). Hölderlin y los griegos. La balsa de Medusa, vol. 96, Madrid: Visor Dis.

Modern, R.E. (1986). Historia de la literatura alemana. Breviarios vol. 159, México: Fondo de Cultura Económica.

Morton, M. (2000). German Romanticism: The Search for $<\mathrm{A}$ Quiet Place>. Art Institute of Chicago Museum Studies, 28 (1) Negotiating History: German Art and the Past.

Naddaf, G. (2009). Algunas reflexiones sobre la noción griega temprana de inspiración poética. Areté. Revista de Filosofía, 21 (1), pp. 51-86.

Nymphomaniac,Dinamarca-Alemania-Francia-Bélgica-Reino Unido, Lars von Trier, Zentropa Heimatfilm, 2014 (película). Onetto M.B. (1995). El apoderamiento de Hölderlin y Nietzsche en la medianoche del mundo. Bochum, 22 de mayo de 1995 (conferencia) http://serbal.pntic.mec.es/ cmunoz11/breno.pdf.

Pacheco, J.E. (1984). Alta traición, en su libro Fin de siglo y otros poemas, Lecturas mexicanas vol. 44, México: Fondo de Cultura Económica.

Pahl, K. (2005). A Reading of Love in Hölderlin's 'Andenken', The German Quarterly, 78 (2), pp. 192-206.

Panzer, F. (1933). Richard Wagner und das Deutschtum. Heidelberg, 13 de febrero de 1933 (conferencia), Fráncfort: Moritz Diesterweg.

Papini, G. (1984). El fin de los perseguidores, en su libro El libro negro, México: Porrúa, $5^{a}$ ed.

Pau, A. (2008). Hölderlin. El rayo envuelto en canción. Madrid: Trotta.

Paz, O. (1983). Piedra de sol, en su libro Libertad bajo palabra, Lecturas mexicanas vol. 4, México: Fondo de Cultura Económica. 
Picard, R. (1962). Poesía del Romanticismo alemán (Dimensiones metafísicas de la poesía alemana del Romanticismo), Convivium, No. 13-14.

Schmitt, C. (1925). Politische Romantik, Múnich/Leipzig: Von Duncker \& Humblot.

Viëtor, K. (1920). Der Bau der Gedichte Hölderlins. Zeitschrift für Ästhetik und Allgemeine Kunstwissenschaft, 14.

Von Hellingrath, N. (1921a). Hölderlin und die Deutschen, en Ludwig v. Pigenot (comp.), Hölderlin. Zwei Vorträge. Múnich: Hugo Bruckmann.

Von Hellingrath, N. (1921b). Hölderlins Wahnsinn, en Ludwig v. Pigenot (comp.). Hölderlin. Zwei Vorträge. Múnich. Hugo Bruckmann.

Voßkühler, F. (2004). Friedrich Hölderlin: Dichtung als neue Mythologie', en Friedrich Voßkühler, Kunst als Mythos der Moderne. Kulturphilosophische Vorlesungen zur Ästhetik von Kant, Schiller und Hegel über Schopenhauer, Wagner, Nietzsche und Marx bis zu Cassirer, Gramsci, Benjamin, Adorno und Cacciari, Wurzburgo:Königshausen \&Neumann.

Zweig, S. (1981). Hölderlin, en su libro Der Kampf mit dem Dämon. Fráncfort: S. Fischer. 
Resumen

El texto propone un método para clasificar la Weltanschauung (visión del mundo) de Friedrich Hölderlin concibiéndolo como bisagra entre tradiciones aparentemente irreconciliables. Evocando los puentes de la ciudad de Königsberg e invitando a pensar la realidad global en la que Europa está inmersa, se ordenan los motivos de su producción poética en siete díadas: Clasicismo y Romanticismo; lo universal y lo nacional; Deutschtum y Griechentum; el hombre y la aspiración divina; lo visible y lo invisible; razón y locura; musa como inspiración y cristalización del ideal.

Palabras clave: Friedrich Hölderlin, Romanticismo, esencia de la poesía, ontología, Weltanschauung, Deutschtum.

\section{Abstract}

The paper proposes a method for approaching Friedrich Hölderlin's Weltanschauung (worldview) conceiving it as a hinge between apparently irreconcilable traditions. Evoking the bridges of Königsberg and inviting to think Europe from a global perspective, this paper also claims that Hölderlin's poetic production can be classified in seven dyads: Classicism and Romanticism; universalism and nationalism; Deutschtum and Griechentum; human being and divine aspiration; the visible and the invisible worlds; reason and madness; muse inspiration and fulfillment of the ideal.

Key words: Friedrich Hölderlin, Romanticism, essence of poetry, ontology, Weltanschauung, Deutschtum. 